\title{
Emerald Drugs and Alcohol
}

\section{Two Buses and a Short Walk: The Place of Geography in Recovery}

\begin{tabular}{|r|l|}
\hline Journal: & Drugs and Alcohol Today \\
\hline Manuscript ID & DAT-08-2015-0045.R3 \\
\hline Manuscript Type: & Research Paper \\
\hline Keywords: & $\begin{array}{l}\text { Recovery capital, Substance misuse, Place, Service provision, } \\
\text { Commissioning, Geography }\end{array}$ \\
\hline \multicolumn{2}{|l}{} \\
\hline
\end{tabular}

SCHOLARONE

Manuscripts 


\section{Two Buses and a Short Walk: The Place of Geography in Recovery}

\section{Purpose}

- As UK substance misuse policy has increasingly focused on the concept of recovery, policymakers, service providers and service users have found 'recovery capital' a useful concept to understand the barriers to and facilitators of recovery from substance misuse. There is a rich strand of research that considers the composition of recovery capital in terms of the relevance of resources such as access to mutual aid, familial support and friendship networks, stable housing, structured psychosocial support and education, training and employment. However, such general accounts have tended not to engage with the potential spatial element of recovery capital; that is, how location contributes to the acquisition and management of recovery capital. This paper therefore seeks to add nuance to more generalised accounts through a critical interrogation, exploration and analysis of the role of geography in recovery.

\section{Design/Methodology/Approach}

- The paper draws on in-depth interviews with service users and service providers in a predominantly rural county in the south-west of England.

\section{Findings}

- The ability to build and sustain recovery capital is shown to be marked by a complex web of social and spatial inclusions/exclusions.

\section{Originality/Value}

- This paper makes three important contributions to prevailing understandings of recovery capital. First, it shows how narratives of recovery are intimately tied to perceptions and experiences of place. Second, it reveals some of the important challenges and complex dilemmas that local drug and alcohol commissioners face in designing and delivering recovery-orientated treatment systems. Third, and finally, it 
argues that there is a pressing need for a more nuanced appreciation of the social and spatial dynamics of recovery capital.

Keywords: recovery capital, place, service provision, drug and alcohol commissioning 


\section{Introduction}

UK substance misuse policy has increasingly focused on the concept of recovery, with a succession of national policy documents making reference to this. The 2010 Drug Strategy was entitled 'Reducing Demand, Restricting Supply, Building Recovery' (HM Government, 2010), and was followed up by the Home Office (2012) document 'Putting Full Recovery First'. Recovery, however, is not a straightforward concept, with different meanings and implications ascribed to it by various stakeholders (Roy and Buchanan, 2015). It might mean abstinence from using psychoactive substances, or perhaps some form of management of problematic substance use. Such variety in definitions is only to be expected given that UK government policy has not taken a clear line, describing recovery simply but vaguely as 'an individual, person-centred journey, as opposed to an end state, and one that will mean different things to different people' (HM Government, 2010: 18).

Despite - or perhaps because of - this diversity of understandings, policymakers, service providers and service users have found 'recovery capital' a useful concept to understand the barriers to and facilitators of recovery from substance misuse. There is a rich strand of research that considers the composition of recovery capital in terms of the relevance of resources such as access to mutual aid, familial support and friendship networks, stable housing, structured psychosocial support and education, training and employment (Duffy and Baldwin, 2013; Neale et al., 2014; Parkman and Lloyd, 2015). However, such general accounts have tended not to engage with the potential spatial element of recovery capital; that is, how location contributes to the acquisition and management of recovery capital.

There is a considerable - and growing - body of work on substance use and geography, particularly since a certain gap was noted by Jayne et al (2006). However, this work has tended to focus on public space and drunkenness, with particular attention paid to the drunkenness and night-time economy as opposed to the concepts of addiction, 
dependence or recovery. In the same year as Jayne et al observed a lack of geographically-informed work on 'alcohol, drunkenness and public space', Wilton and DeVerteuil suggested that although there had been 'interest in geographical variations in alcohol use and their implications for health, similar attention has not been given to geographies of alcohol treatment and recovery' (2006:649). It is our contention that this gap in the literature in relation to treatment and recovery remains, and that a need for analysis of this is particularly pressing given the adoption of the concept of 'recovery' as a cornerstone of UK government substance misuse policy.

This article should therefore be read as a response not only to the theme of this special edition, but also to Roy and Buchanan's (2015) call to 're-politicize drug debates and recognize the structural and demographic factors which frame problem drug use, as well as the social and cultural factors which support or negate their opportunities for recovery'. As such, this article seeks to add nuance to more generalised accounts through a critical interrogation, exploration and analysis of the role of geography in recovery.

For the purposes of this paper, therefore, we accept the definition of recovery outlined in the 2010 Drug Strategy with all its potential variability. That is, individuals define for themselves what recovery means to them and where they (or others) are on that journey. We take this position because, as detailed below, this article is based on research that was concerned with the perceptions of service users and staff, and we start with these perspectives. Our aim here is to understand how ideas of place can be found in those understandings of recovery, rather than defining recovery in advance and see how achievement of this is affected by particular understandings of place. The paper should therefore be seen as complementing - rather than directly contributing to - the ongoing critical debate regarding the various definitions of recovery (for an important overview see Monaghan 2012; Duke et al., 2013). By outlining how place affects and structures understandings of recovery, we want to do more than suggest that different areas face particular local challenges; we wish to draw attention to how recovery discourses are 
inevitably 'located', which is distinct from them being 'local'. That is, whether the challenges of a place are unique (or perceived to be), they are certainly perceived as set in a particular context, and therefore should be addressed with an understanding of place. If we are to address substance use in Dorset, for example, we must do so with an understanding of how the place in which people may or may not sustain recovery is understood.

\section{Ideas of Place}

We follow Duff in seeing place as 'composed in diverse actor networks, facilitating access to enabling resources and supporting the development of novel agencies or capacities' (2011:149). That is, whether a place is more or less 'enabling' of recovery depends not simply on objective or material characteristics, but also on how it is understood by the people within it, and how they interact.

This paper considers whether and how Dorset is viewed as an 'enabling' place for recovery, and is therefore structured to match Duff's model for thinking about places and their associated resources, which he divides into material, affective and social. Informed also by William White's (2009) proposed framework for understanding the 'ecology' of addiction, we take the category of 'material' to include physical resources, and that of 'affective' to include cultural resources.

Examples of material resources might include an individual's income or wealth to support them, but also the resources of a treatment system in terms of the staff or facilities on offer. These would be affected by local budgets and policy decisions. In addition, the landscape itself might be a help or hindrance - potentially depending on how it is understood by those engaging with it. For one person an isolated location could make communication difficult, but for another such a space might act as a sanctuary. 
Affective or cultural resources might include the way one approaches certain aspects of life - for example if there is a supportive shared understanding of the nature of substance misuse. In terms of place, one can immediately see that such shared understandings or resources might have a geographical scope to their power or resonance, with those within a particular culture subscribing to a particular belief. This resource (or lack of it) might relate to a geographical area rather than substance use in general, if there is a particular feeling of a local recovery community, or a local policy consensus regarding substance use.

Finally, social resources might also be understood as social capital: the connections one has with other human beings (Bourdieu, 1984; Putnam, 2000). As such, social resources are closely linked to affective resources: the existence of a supportive body of social connections for recovery, and might include fellowship or social groups.

In this way, one can quickly see that all the types of 'place' are abstractions that separate different elements of what it is to 'be' in a location. As will be discussed, research participants made a strong case for the value of peer support:

We all know how frustrating the system is down here; we have all been through it. So we have kind of found that the best support that we can get is each other, which is why a lot of people come here every day (Lucinda).

Such support can be seen as depending on all three forms of resource. One needs the physical resources (whether through an internet connection or buses and a church hall) to access the social resource of peers, and the cultural resource of there being a positive shared understanding of 'recovery'. 


\section{Background to the research}

The research on which this paper is based springs from a call for research proposals by Dorset Drug and Alcohol Action Team (DAAT) in 2014. ${ }^{1}$ This call outlined the following research questions:

- What do different stakeholders within the Dorset treatment system understand by the term 'recovery', and what is its relevance for their practice/behaviour?

- What difficulties do current service users who have been in treatment for more than 4 years in Dorset face in supporting their recovery?

- What local factors affect individuals' ability to sustain recovery, having completed substance misuse treatment successfully?

- How well do treatment services currently available address these issues?

- How do the policies and practices of local partners affect individuals' ability to achieve and sustain recovery?

- Does a service user's chance of achieving and sustaining recovery vary by:

○ Locality

- Gender

- Substance used

Dorset has a variegated drug and alcohol treatment system, with four main service providers commissioned to deliver structured treatment. These services are commissioned through the County Council, previously via the DAAT, and now at the time of writing through Public Health Dorset. This latter organisation operates not only within the two-tier local authority area of Dorset County Council, but also across the neighbouring unitary local authorities of Bournemouth and Poole. At present there

\footnotetext{
${ }^{1}$ The study upon which this article is based focused exclusively on Dorset's six shire districts: Weymouth and Portland, Purbeck, East Dorset, North Dorset, West Dorset and Christchurch. Therefore it does not concern itself with the unitary authorities of Bournemouth and Poole, which are self-governed on local issues, while remaining part of the ceremonial county of Dorset.
} 
remains a single treatment system for the County Council area, and all references to Dorset in this paper should be read as referring to this area.

A community NHS provider offers a county-wide service for people requiring treatment for dependency on alcohol or illegal or prescribed drugs. It offers a suite of services which include structured treatment with psychological and social support; prescribed medication where appropriate, access to community and in-patient detoxification, access to residential rehabilitation, access to blood borne virus (BBV) testing and immunisation and access to liver treatment services.

A regional charity provides recovery-focused psychosocial support through one-to-one and group sessions in Blandford, Bridport, Christchurch, Gillingham, Swanage and Weymouth. Outreach services are also available at locations including Dorchester, Ferndown and Wareham.

A local charity provides structured treatment support to individuals and their families through a focus on building recovery from addiction and assisting with relapse prevention. It provides one-to-one and group support across Dorset. Practically it provides advice to support employment, education, finance and health.

A national charity provides a community-based service for drug users currently engaged with the criminal justice system, for example on a community sentence or awaiting trial. This service offers multi-disciplinary interventions to drug users and a tailored route into treatment for this client group. Each individual is provided with a 1:1 worker and an individual care plan which can include treatment plans, advice, social and leisure activities, and ongoing support in and out of prison. 
Historically a block contract system has operated with an NHS inpatient detoxification facility, across three local authorities (Bournemouth, Poole, Dorset), such that all ten beds were held for service users in these areas, at a fixed per annum cost for keeping the whole facility running. As of April 2015 Dorset moved to a Dynamic Purchasing System (DPS) with a range of providers - effectively spot-purchasing, whereby an individual will have their placement approved by a multi-disciplinary team meeting, and then will be able to choose from a list of appropriate approved providers.

In addition to commissioned treatment services, Dorset also has a vibrant mutual aid infrastructure. Fellowship programmes are provided by Narcotics Anonymous and Alcoholics Anonymous, while the SMART Recovery network advocates a secular and science-based approach to behaviour change. The Pier, a service led by service users, for service users, was set up by Dorset Service User Forum in partnership with the Dorset Drug and Alcohol Action Team in 2011.

From the evocation of woodland communities and stultifying social conventions, Hardy's Wessex novels have shaped the cultural and imaginative landscapes of Dorset. The Victorian realism of Hardy's writing sits alongside contemporary renderings of Dorset as a place of bucolic charm and moneyed leisure. This alluring picture serves, in part, to mask concentrations of severe multiple disadvantage (LankellyChase, 2015). Analysis conducted for local commissioners has suggested, in line with national research, that substance misuse in Dorset is closely associated with key variables such as employment, deprivation, and demographic groupings as provided by resources such as MOSAIC (Dorset DAAT 2012; Dorset County Council 2013).

A small body of critical scholarship has drawn attention to the presence of 'geographies of exclusion' (Sibley, 1998) within the literal and fictive landscape of Dorset. This commitment to unpicking the social and spatial complexity of Dorset is evident in Whiteford's (2010) writings on rough sleeping and Fenge et al's (2010) mixed method investigations into older lesbian and gay men in rural communities. Haydock (2014) has 
similarly described how the management of Bournemouth's night-time economy is mediated through reference to competing notions of class and cosmopolitanism. From a different angle, Tobias Jones (2008) has explored the way in which Pilsdon, a community of prayer, hospitality and work located deep in the West Dorset countryside, is perceived and experienced as a therapeutic landscape for people struggling with entrenched addictions. These studies clearly illustrate how particular groups and forms of behaviour come to be viewed and understood as 'matter out of place' (Douglas, 2002), but also equally serve to capture the dynamic role of place as a barrier to and facilitator of material, affective and social resources. In the following sections, we seek to attendand further contribute - to this line of inquiry.

\section{Methodology}

The study on which this paper is based used thematic analysis (Boyatzis for an overview, 1998). Interview transcripts were systematically searched for patterns in order to develop meaningful themes. This analytical approach led to specific attention being directed towards the way in which perceptions and experiences of recovery are influenced and shaped by 'place'. Data analysis was performed using the Atlas Ti qualitative software package.

\footnotetext{
A total of 14 service user interviews were carried out across Dorset (10 long-term opiate users, 3 with a history of alcohol misuse and 1 habitual skunk cannabis user). Of the 14 participants, 11 were male and 3 were female. Ages ranged from 24 to 60 . The majority of participants were in receipt of Disability Living Allowance (DLA), Employment and Support Allowance (ESA) or Jobseeker's Allowance. Most were also entitled to Housing Benefit payments. A small minority of service users were actively engaged in voluntary work and/or purposefully involved in peer mentoring.
} 
Service user interviews were carried out face-to-face in private rooms within treatment centres to ensure confidentiality. Interviews were semi-structured and lasted between 30-60 minutes. All interviews were audio recorded with the consent of the service users. Each participant was given a pseudonym to protect their anonymity. Research participants were paid in high street vouchers (equivalent to $£ 15$ ) for giving-up their time and sharing their expertise.

In addition to service user interviews, 10 stakeholder (4 service managers, 2 nurse prescribers, 2 peer mentor coordinators, 1 service commissioner and 1 mental health practitioner) interviews were conducted across Dorset. Following the work of Duke et al, we understand 'stakeholder' to mean '[an] individual, group or network of people involved with, or with interests in, or affected by a particular area of activity or a particular policy' (2013:968). Stakeholders were recruited with a view to ensuring that different geographical contexts (e.g. coastal, rural and metropolitan) and models of service provision (i.e. prescribing services, psychosocial support, aftercare and recovery services and the local drug interventions programme) featured in the study. All research participants were allocated a generic working title in order to safeguard their identity. Interviews were conducted on a face-to-face to basis in a private room at the participant's workplace or, alternatively, in a designated conference room at Dorset County Council's headquarters. Interviews lasted approximately 30-45 minutes. Fieldwork was undertaken between December 2014 and February 2015.

Ethics committee approval was obtained from the National Research Ethics Service (REC number 14/SW/1003)), Dorset County Council (MW140514) and the University of Liverpool (UoLooo947). 


\section{Findings}

\section{Material or physical resources}

Public services are operating at present in an environment of considerable financial challenges. The UK government's policy of austerity means that organisations across the public sector are facing significant financial challenges. In addition to budget reductions, demographic changes look likely to increase the need for services, in particular adult social care as the population ages. This specific development poses particular challenges for substance misuse commissioners and providers, as substance misuse services are now a local authority responsibility alongside adult social care since the transition of public health budgets to local authorities in 2013. This dual effect on local authorities of rising predicted expenditure in parallel with cuts in budgets has been noted by the Local Government Association (2015), as shown by the graph copied below. In addition to this background of cuts to public sector spending, 2015 has seen the announcement of inyear cuts to Public Health budgets of 6.2\% (Department of Health, 2015), and substance misuse treatment is the largest single item within those (Local Government Association, 2014).

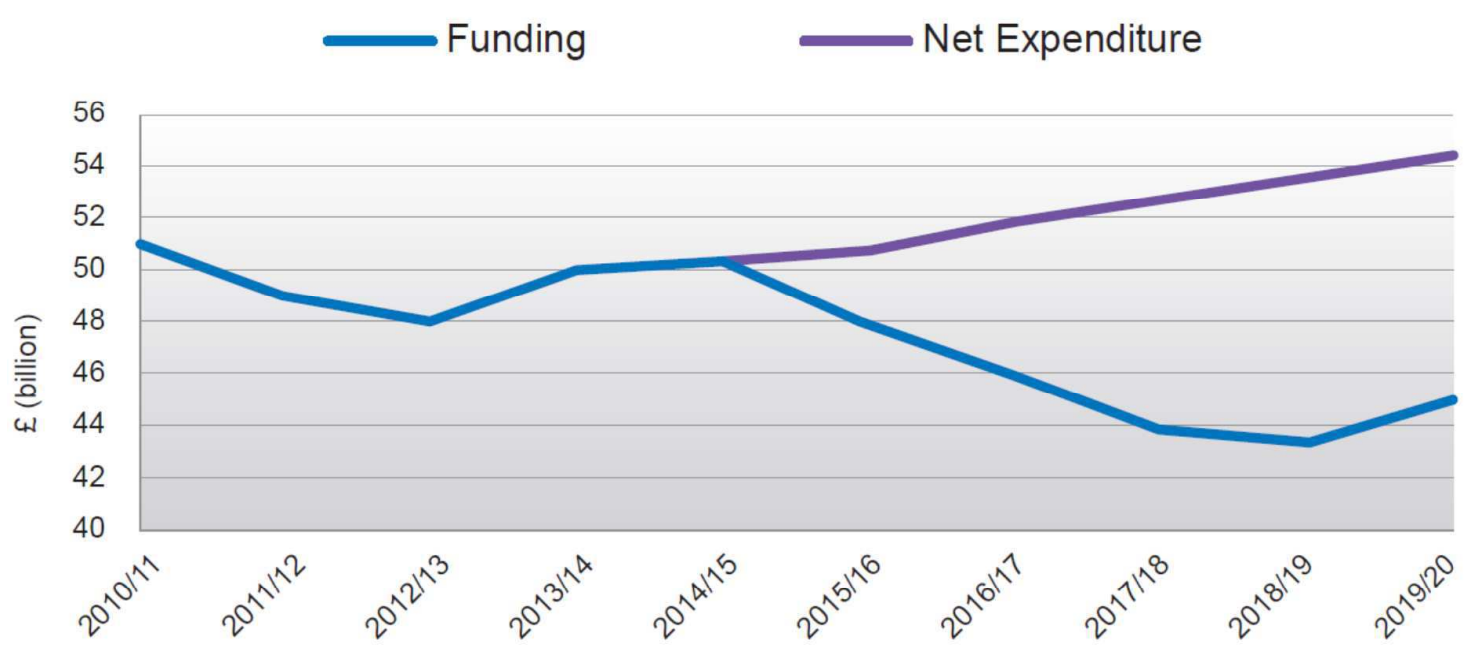

Figure 1: Local authority income against expenditure, 2010/2011 - 2019/2020 (taken from Local Government Association 2015: 13). 
This should not be seen as simply an issue for this service user group in terms of substance misuse treatment, or even wider local authority services. Recovery capital, as understood here, comprises a wide set of resources, covering services supported by local authority funding such as some educational grants, transport and housing, but also support from other public sector organisations facing challenges, such as mental health care, employment support including benefits, and supervision through the services replacing probation.

This financial situation places particular challenges for local authorities in meeting their duty as responsible for public health outcomes to narrow health inequalities. However, local commissioners would argue that they are responding to these changes in creative ways, seeking to respond to the 'cracks and fissures of neoliberalism' by advancing a form of progressive localism (Crisp, 2015). For example, use is made of peer mentoring support projects, such as the Pier Project that provides a social hub at weekends for those with substance use issues, outside the operating hours of statutory support services.

Moreover, this paper is concerned more with perceptions of such challenges as they affect service users and other stakeholders' perceptions of Dorset. And there is little doubt that the political and economic environment has affected service user perceptions of the resources available to them in Dorset. As one participant put it:

With mental health they shut half the places down due to cut-backs. They used to have a ward up here that used to detox me and help me with my mental health. I used to have a very good counsellor up there but he has left now since all these cutbacks and things. These services need to buck their ideas up. I presume they need a lot of financial back-up and they need places for people to go. But there is one place in the whole of Dorset, which I think gets one bed or something every few months, so what chance have you got (Alec). 
Commissioners would challenge such an understanding of resources, as there have been no cuts in funding to detoxification or inpatient facilities - indeed numbers going through detoxes have increased in recent years - but the perception is certainly real. And more than this, it highlights a point worth noting: even physical or material resources are mediated by perception. That is, the effect of a cut will be shaped by perceptions of the service available, not simply their material value.

Material and physical resources are not limited to funding available for services, or even those services themselves. Services and individuals operate within a physical environment, which in the case of Dorset county is a rural area with all the associated challenges as well as benefits. As a commissioner stated, there is not the 'critical mass' of potential service users to have a significant service within easy reach of every Dorset resident, and even where services are available, they may be of a quite different kind to those centralised in a large town or city:

If you are an individual living in [small town] you just don't have the same opportunities or access to the same service configuration. You can imagine the situation where you have a totally different set up in Bournemouth because there is the critical mass; people can make it into a single point of contact. [That situation] is just not possible for rural Dorset, so you would need to have something available for the individual living in Blandford or a surrounding village. Therefore it is not so much about quality as options, so making sure that you are not giving someone the option to have something in one area, but then not offering it somewhere else (Service commissioner).

Service providers are certainly aware of these issues, as they work with them every day:

Getting people into treatment if they live in a village can be difficult. Initially we want to safely prescribe to people and we would encourage them to be on daily supervised consumption. If they haven't got a chemist in their area or haven't got the support because they are in a village that is quite isolated it can be very hard (Nurse prescriber).

Service users themselves are also well aware of these challenges: 
The using community in [large town] has nothing special about it; it is pretty much the same anywhere. Anywhere I have used it is pretty much the same... I have lived in a lot of cities and the user community is pretty much just the same. The services on the other hand, I don't think they know what they are responding to, or how to respond really. But it is different in [terms of] the geographical area. It is a lot more spread out and there are a lot of rural communities and stuff like that...I mean when I first came down I used to have to go to [a small village] to score (Theodore).

This shared understanding of the logistical and organisational difficulties associated with providing structured treatment across a largely rural environment was also seen to intersect with more practical concerns, as the following interview extract reveals:

The cost of the travelling and the parking [is prohibitive]. Last week I tried to avoid paying the car parking to save some money. I tried to park in the tiny car park at the back of here, but it was so packed and so tight that I ended scratching my car badly. If I get that repaired I am sure it's going to cost a few hundred where as you know it was a pound or something for the car park (Angela).

To some extent these challenges may appear inherent in the landscape - or at least in the built environment staff and service users find themselves in. However, the way in which services operate is determined by the interpretation of possibility within these spaces, and some staff take a more positive, asset-based approach:

I work in GP surgeries; I go and see people in their house, their homes, anywhere they need to meet. Some people I meet in a lay-by. One of my patient's works and I can only catch him in his dinner hour, so we meet in a mutual place that is half-way. It doesn't matter where you meet people; it is what happens (Nurse prescriber).

\section{Social resources}

Social capital, however understood (Bourdieu, 1984; Putnam, 2000), has been identified as a key resource within recovery capital. Indeed this could be seen by fellowship groups 
as simply a rebranding of a resource they have stated for decades as being central to sustaining recovery: peer support:

We all know how frustrating the system is down here; we have all been through it. So we have kind of found that the best support that we can get is each other, which is why a lot of people come here every day (Lucinda).

This commitment to peer support - or social capital - was strong beyond those individuals who find it on their doorstep. Some made considerable efforts to access such networks, leading to the title of this paper:

I've lost my car and have to get two buses to get over here. I've been going to the [small urban district] group every Monday, so I've been coming to [the drop-in] at least three times a week and that makes a big difference. I want to get clean and that makes a big difference. I listen to people and since I've got clean I just want to talk all the time. If I hadn't had these groups to come to I would just be sat at home. I've come so far and I just don't want to be stagnant (Max).

However, this social capital is cross-cutting with the other elements of recovery capital and place. Service users and commissioners described how developing supportive communities was much more straightforward - and had been much more successful - in the largest town in the county:

We are hoping to extend across the county. It is proving quite difficult at the moment because we haven't got bases anywhere else. [Large town] is quite a big recovery base. We have had attempts at setting up in other areas, though it seems that people are enthusiastic until they know what is involved (Peer mentor coordinator).

We have got quite a few fellowship groups in different areas of the county. We have also got a growing network of Smart groups. Hopefully in the next few years [some of these groups] will be self-sustaining and autonomous. In terms of service user organisation and general mutual or peer support, I think that could be stronger. We have a little bit in [large town], but it is pretty much a desert outside of that (Service commissioner).

Even in this town, however, there is a particular character to this social element to place: 
In [large town] there is a very, very strong recovery community, very strong but not very visible (Theodore).

This network is, in Putnam's terminology, a form of 'bonding' social capital, which generates strong links between members of a group. However, the lack of visibility suggests that there is little 'bridging' social capital - that is, links outside of this close-knit group to individuals more widely.

\section{Affective or cultural resources}

Just as the landscape does not simply offer challenges or opportunities unmediated by responses to this environment (Duff 2011), social connections in themselves may be supportive or unsupportive; that depends upon the cultural and affective approach taken by those individuals. Rural environments are often viewed as inherently therapeutic places, with little anomie or social problems, but this may not always be the case. The close-knit community seen as characteristic of small rural communities can be both stigmatising and supportive, in different measures. Daniel noted that being visible locally as a user of substance misuse treatment was not always (or ever) a positive experience:

I come here every morning and on my way here I see the same people walking the same route almost in the same footsteps every morning going to the same place. And I used to be one of them, [but now] it is a case of I don't want it. In Boots the other day someone offered it to me; put it under my nose and I hadn't used for 6 weeks and they put it under my nose. It was easy for me to say no but there are a lot of people that wouldn't be able to say no. But when you go to Boots to pick up your script you are singled out straight away because you don't shop with everyone else. You have got a little window there with two bits of glass at the counter and open shutters for everyone who gets methadone, but if there is a big long queue and the pharmacist is out the back doing checks she deals with you before that person there, so they then start talking about you.

Such an approach also affects political decision-making. This is not a study of local policymaking processes, as recommended by Haydock (2015), and so we do not attempt 
to identify the effects of this affective response to the landscape or environment in depth here. However, such challenges are certainly perceived by service users within the local treatment system. One noted that certain local officials refuse to associate substance misuse with their local area:

I can remember a local council within Dorset that said: 'we haven't got a drug problem in this part of the county'. And yet, their area was flagged up nationally. I couldn't believe it when I heard that. [These] areas don't have drug and alcohol problems because they don't want them. They are there, but they don't want them there (Peer mentor).

Such a response suggests a lack of affective or cultural support for those seeking to recover from substance misuse. It was generally identified by participants that need not mean a lack of recognition for local substance misuse issues - and indeed the currently commissioned services would suggest there is considerable acknowledgement of these.

\section{Discussion: 'exhilarating, and strengthening, and soothing' or a 'cruel taskmaster'}

As Duff (2011) notes, rural places are often seen as inherently 'therapeutic places', and yet one person's understanding of a location may differ substantially from another's. To take the Dorset heath, as described in Thomas Hardy's (2008) Return of the Native; while this is for mobile, male Clym Yeobright, recently returned from Paris, 'most exhilarating, and strengthening, and soothing', Eustacia Vye sees it as a prison, that is a 'cruel taskmaster', keeping her isolated, far from her desires.

There may be something of a parallel of this story in the way rural landscapes appear in discourses of recovery. One local residential rehabilitation centre for addiction, for example, just outside Dorset, describes itself as 'set in a naturally therapeutic environment of beautiful Wiltshire parkland'. Living full-time in such a geographical location, however, poses its own challenges, as discussed above. In a residential treatment setting, the treatment fee has (it is to be hoped) paid for physical, affective 
and social resources to be in place to support that individual's recovery. Without the critical mass of individuals in a rural location, and with a need for effective transport links, this does not apply when someone lives in this location. Moreover, as Theodore noted (quoted above), such areas are not so isolated that there is no temptation; he used to specifically go to a small village to 'score'.

What makes this space therapeutic, therefore, is not so much the physical setting, but the wider resources attached to it (Gesler, 1992). That is, without the structure and social capital offered by a residential recovery community, the challenges of sustaining recovery are manifold. As one participant in our research stated of his experience in a rural recovery community:

While I was there I was asked if I wanted to become a part of the community, but at that time I actually felt that being that isolated wouldn't be good for me. And, yes it was all very nice and it was very safe, and it was very good being there...I did enjoy being there, but I felt that to be taken that far out of society would be detrimental [to my recovery] at that time. You know, I needed to be around people, I needed to start getting my life back on track as much as possible and I thought that being that isolated out there, even though you have a set routine during the day where you work around the farm, but I didn't feel that that was right for me from a point of abstinence. Yes it was perfect, it was brilliant, but I felt that if I needed to be in normal society where I can accept that: yes there are pubs open, there are off licences, I have to deal with that again (Nigel).

There is, therefore, a dual issue with rurality as a 'therapeutic' setting for fostering recovery from substance misuse. First, living every day in an isolated location can be, quite simply, isolating, if one lacks a local support network. Second, and more generally, the 'therapeutic' value of a stay in rehab rests on the structure of the programme, which may be lacking in one's everyday life.

The challenge, therefore, in fostering recovery in rural settings, is to ensure that some form of these social and cultural resources are embedded in local communities. The close-knit community that means Daniel is recognised - and stigmatised - when collecting his methadone need not be a negative influence; it could be mobilised for 
positives. Contrast this with the recovery community described in the larger town, which is 'very strong' according to Theodore, if not very visible. There may not be enough people in smaller towns and villages to make up a standalone recovery community, but if we look at the local community as a potential asset, rather than a stigmatising force, then the 'recovery community' could be wider than those building their own recovery from substance misuse. A community supportive of recovery is surely in one sense a recovery community. If the community one benefits from within a residential rehabilitation unit is in some sense manufactured, in order to produce support, then perhaps commissioners and others, when thinking about 'building recovery in communities' (NTA 2012), should think about manufacturing communities in the wider setting.

We wish to add one caveat to this analysis. There is a difficult political and moral balance to be struck as to how commissioners and service providers might respond to the 'place' they find themselves in, as regards physical, social or affective resources. While we might accept that, in the medium term at least, many elements of these are fixed, a view must be taken in terms of what features are changeable, and how much effort should be expended in fostering that change. There is a sense in which accepting certain features such as limited or stretched public transport services - can be seen as facilitating a particular political agenda. Or perhaps a focus on social capital might seem a poor substitute for the physical resource of well-funded public services.

However, even if we would not start from here, we must. And we are not suggesting that material resources are unimportant; merely that there are other potential resources which should be drawn on to maximise people's opportunities for recovery in rural settings. Where beneficial changes can be made, they should be, and there is evidence that local stakeholders are well aware of the political implications of their decisions:

Services are provided for a particular gap, which is for those people who are lacking in certain forms of what you might call recovery capital. So, I don't want to design our services for people who are likely to have more recovery capital. We know that all those 
things are more associated with wealth. So if you are talking about stable housing, stable employment, stable income, stable relationships those seem to be correlated [to indices of deprivation]. And when you look at some of those things I don't think that we have got that in Dorset. I don't think housing provision is strong enough. I don't think the economy in [large town] or other areas is strong enough to be able to realistically offer stable housing, stable employment and those kinds of things. At the same time, we could probably do more to advocate for that and that is what treatment systems should really be providing not just some form of medical or drug-related treatment (Service commissioner).

\section{Limitations}

This was an exploratory investigation into barriers to and facilitators to recovery from substance misuse in a specific geographical location. Whilst the research findings presented clearly relate to the localised example of Dorset, we would suggest that there are broader points about how understandings of recovery and the resources available to support this are affected by characteristics of place - physical, affective and social - and in consequence of this have the potential to find resonance with communities with similar characteristics and a concomitant interest in establishing a 'local culture of recovery' (Roy and Buchanan, 2015).

It should also be noted that service user recruitment was restricted to three research sites across the county. Linked to this, gatekeepers assumed a prominent role in identifying and recruiting research participants. There is every reason to believe that service users' who agreed to participate in the study held particularly strong opinions and/or felt motivated by a sense of duty and responsibility. It is also possible that the use of financial incentives may have skewed recruitment.

The study was also weakened by its failure to capture the full range of institutional actors involved in recovery management in Dorset. Stakeholder interviews were limited to the most prominent organisations and individuals. It is arguably the case that reliance on convenience sampling provides a partial and incomplete picture of the Dorset drug treatment system. 


\section{Conclusion}

Notwithstanding the above caveats or conditions, we would suggest that the strength of the present study is apparent in the way it contributes to the growing corpus of literature on barriers to recovery through its engagement with the role of geography in recovery. We would further contend that there is a need for scholarship that actively grapples with what Evans and his colleagues refer to as the 'place-bound properties that make a difference in the recovery journeys of clients' (2015:118). Elsewhere Daniel Briggs (2015) has strongly argued for the ethical and empirical value of ethnographic research that is concerned with the lived reality of drug use. In the work of Briggs (See also 2012) and Wakeman (2015) - to take just two recent examples - we can discern a clear sensitivity towards the importance of local texture and quotidian practices. There might, for example, be value in future research that ethnographically considers how people struggling with the physiological and psychosocial effects of substance misuse are forced to negotiate the everyday geographies of recovery. From a complementary perspective, we might also see merit in pursuing institutional or policy ethnographies which are attentive to the role of geography in facilitating the acquisition of recovery capital within predominantly rural communities. What seems certain, though, is as understandings of recovery evolve (Lancaster et al., 2015:625), so must our methodological and conceptual lenses. 


\section{References}

Best, D., Bird, K. and Hunton, L. (2015) Recovery as a Social Phenomenon: What is the Role of Community in Supporting and Enabling Recovery? Sheffield: SHURA.

Bourdieu, P. (1984) Distinction: A Social Critique of the Judgement of Taste. London: Routledge.

Boyatzis, R. (1998) Transforming Qualitative Information: Thematic Analysis and Code Development. Thousand Oaks: Sage.

Briggs, D. (2012) Crack Cocaine Users: High Society and Low Life in South London. London: Routledge.

Briggs, D. (2015) Living Realities: the importance of ethnographic drug research, Drugs, Education, Prevention and Policy, Vol. 22 Issue 3 pp. 308-310.

Crisp, R. (2015) Work clubs and the big society: reflections on the potential for 'progressive localism' in the 'cracks' and 'fissures' of neoliberalism, People, Place and Policy, Vol. 9 Issue 1, pp. 1-16.

Department of Health (2015) Local authority public health allocations 2015/16: in-year savings, A consultation. Available from https://www.gov.uk/government/uploads/system/uploads/attachment_data/file/450508/ Cons_doc_HA_version.pdf [Accessed 08-10-2015] 
DeVerteuil, G. and Wilton, R. (2009) The geographies of intoxicants: from production and consumption to regulation, treatment and prevention, Geography Compass, Vol. 3 Issue 1, pp.478-492.

Dorset County Council (2013) DDAT Service Users - Mosaic Analysis. Unpublished, available on request.

Dorset Drug and Alcohol Action Team (2012) Dorset Adult Substance Misuse Needs Assessment 2011/12. Unpublished, available on request.

Dorset Drug and Alcohol Action Team (2014) A Call for Proposals: Barriers to Recovery from Substance Misuse in Dorset. Dorchester: Dorset County Council.

Douglas, M. (2002) Purity and Danger: An Analysis of Concepts of Pollution and Taboo. London: Routledge.

Duke, K., Herring, R., Thickett, A. and Thom, B. (2013) Substitution treatment in the era of 'recovery': an analysis of stakeholder roles and policy windows in Britain, Substance Use and Misuse, Vol. 48 No. 11, pp. 966-976.

Duff, C. (2011) Networks, resources and agencies: on the character and production of enabling places, Health \& Place, Vol. 17 No. 1, pp. 149-156.

Duffy, P. and Baldwin, H. (2013) Recovery post treatment: plans, barriers and motivators, Substance Abuse Treatment, Prevention, and Policy, 8:6 http://www.substanceabusepolicy.com/content/8/1/6 
Evans, J., Semogas, D., Smalley, J. and Lohfeld, L. (2015) 'This place has given me a reason to care': Understanding managed alcohol programs as enabling places in Canada, Health \& Place, Vol. 33 pp. 118-124:

Fenge, L.A., Jones, K. and Read, R. (2010) Connecting participatory methods in a study of older lesbian and gay citizens in rural areas, International Journal of Qualitative Methods, Vol. 9 No. 2 pp. 320-330.

Gesler, W. (1992) Therapeutic landscapes: medical issues in light of the new cultural geography, Social Science \& Medicine, Vol. 34 No. 7, pp. 735-746.

Granfield, R. and Cloud, W. (2001) Social context and natural recovery: the role of social capital in the resolution of drug-associated problems, Substance Use and Misuse, Vol. 36 No. 11, pp. 1543-1570.

Hardy, T. (2008) The Return of the Native. Oxford: Oxford University Press.

Hay, G. Anderson dos Santos, R. Worsley, J. (2014) Estimates of the Prevalence of Opiate Use and/or Crack Cocaine Use, 2011/12: Sweep 8 report. Liverpool: Liverpool John Moores University.

Haydock, W. (2014) The 'civilising' effect of a 'balanced' night-time economy for 'better people': class and the cosmopolitan limit in the consumption and regulation of alcohol in Bournemouth, Journal of Policy Research in Tourism, Leisure and Events, Vol. 6 No. 2, pp. 172-185. 
Haydock, W. (2015) UK substance use policy should think locally, Drugs and Alcohol Today, Vol. 15 Issue 3 pp. 149-157.

HM Government (2010) Drug Strategy 2010: Reducing Demand, Restricting Supply, Building Recovery: Supporting People to Live a Drug Free Life. London: Crown Publications.

Home Office (2012) Putting Full Recovery First. London: Crown Publications.

Jayne, M. (2006) Cities and Consumption. London: Routledge.

Jones, T. (2008) Utopian Dreams. London: Faber and Faber.

Lancaster, K. Duke, K. And Ritter, A. (2015) Producing the 'problems of drugs': a crossnational comparison of 'recovery' discourse in two Australian and British reports, International Journal of Drug Policy, Vol. 26 Issue 7, pp. 617-625.

LankellyChase (2015) Hard Edges: Mapping Severe and Multiple Disadvantage: England. London: LankellyChase Foundation.

Local Government Association (2014), Local Government Association briefing: Provisional Local Government Finance Settlement 2015-16, available at: http://www.local.gov.uk/documents/10180/5533246/LGA+On+the+Day+briefing+Provision al+LG+Finance+Settlement-201516.pdf/4ce0905f-d881-4426-8a7b-9755ec6d26bc (accessed 21-02-2015). 
Local Government Association (2015) Future funding outlook for councils 2019/20 Interim 2015 update. London: Local Government Association. Available from http://www.local.gov.uk/web/guest/publications-list//journal_content/56/10180/7356229/PUBLICATION [Accessed 25-09-2015]

Monaghan, M. (2012) The recent evolution of UK drug strategies: from maintenance to behaviour change? People, Place and Policy Online, Vol. 6 No. 1 pp, 29-40.

Neale, J., Finch, E., Marsden, J., Mitcheson, L., Rose, D., Strang, J., Tompkins, C., Wheeler, C. and Wykes, T. (2014) How should we measure addiction recovery? Analysis of service provider perspectives using online Delphi groups, Drugs: Education, Prevention and Policy, Vol. 21 No. 4, pp. 310-323.

Parkman, T.J. and Lloyd, C. (2015) Mutual dependence and the 'goldilocks group': exploring service user dependency on mutual aid recovery groups, Drugs and Alcohol Today, Vol. 15 Issue 1 pp. 49-58.

Public Health England (2015) Review of Drug and Alcohol Commissioning: A Joint Review Conducted by Public Health England and the Association of Directors of Public Health. Available at http://www.nta.nhs.uk/uploads/review-of-drug-and-alcohol-commissioning2014.pdf [First accessed 11 June 2015].

Putnam, R. (2000) Bowling Alone: The Collapse and Revival of American Community. New York: Simon \& Schuster. 
Roy, A. and Buchanan, J. (2015) The paradoxes of recovery policy: exploring the impact of austerity and responsibilisation for the citizenship claims of people with drug problems, Social Policy and Administration, doi: 10.1111/spol.12139

Sibley, D. (1995) Geographies of Exclusion. London: Routledge.

Wakeman, S. (2015) Prescribing heroin for addiction: some untapped potentials and unanswered questions, Criminology and Criminal Justice, Vol. 15 No. 5 pp. 578-593.

White, W. (2009) The mobilization of community resources to support long-term addictions recovery, Journal of Substance Abuse Treatment, Vol. 36 Issue 2, pp. 146-158.

Whiteford, M. (2010) Hot tea, dry toast and the responsibilisation of homeless people, Social Policy and Society, Vol. 9 No. 2, pp. 193-205.

Wilton, R. and DeVerteuil, G. (2006) Spaces of sobriety/sites of power: examining social model alcohol recovery programs as therapeutic landscapes, Social Science \& Medicine, Vol. 63 No. 3, pp. 649-661. 